\title{
Production of Biodegradable Plastic Packaging Film from Cassava Starch
}

\author{
S. L. Ezeoha ${ }^{1}$ and J. N. Ezenwanne ${ }^{2}$ \\ ${ }^{1,2}$ Department of Agricultural and Bioresources Engineering, University of Nigeria, Nsukka
}

\begin{abstract}
Materials used for food packaging today consists of a variety of petroleum-derived plastic polymer, metals, glass, paper and board, or combinations thereof. Among these packaging materials, plastic is found to be the best because of its long life properties. Thus, its utilization is increasing every day by day. However, plastics cannot be degraded by natural processes in a short period of time; therefore, they are left as plastic waste, causing environmental problems. Methods normally used to destroy other types of waste such as burning and burying are not suitable for plastic destruction. In response to these problems associated with plastic waste, there has been considerable interest in the development and production of biodegradable plastics. In this work, a biodegradable plastic film was produced by blending cassava starch and a synthetic biodegradable polymer (PVA). The film produced was found to have a biodegradability of $41.27 \%$ compared to $10.33 \%$ and $85.99 \%$ for polythene and paper respectively. The film also has a tensile strength of $24.87 \mathrm{~N} / \mathrm{mm}^{2}$ compared to $10.86 \mathrm{~N} / \mathrm{mm}^{2}$ and $8.29 \mathrm{~N} / \mathrm{mm}^{2}$ for polythene and paper. The potential of producing biodegradable packaging plastic film from cassava starch is encouraging and should be further explored especially in a country with high cassava productivity, like Nigeria.
\end{abstract}

Keywords: - Biodegradable packaging, cassava starch, plastic film, polymer

\section{INTRODUCTION}

Nowadays, plastic utilization is increasing rapidly. This is because plastics can be used in many applications such as packaging, automobile parts, etc. The need for such large quantities of conventional plastics and their dominance over other materials is due to their excellent "long life" properties. These properties include resistance to chemical reactions, especially enzymatic reactions. For example, it can take up to one hundred years to degrade only a few grams of plastic (such as polyethylene) under normal environmental conditions. Because plastics cannot be degraded by natural processes in a short period of time, they are left as 'plastic waste', causing environmental problems. Methods normally used to destroy other types of waste such as burning and burying are not suitable for plastic destruction. When some types of plastics are burnt, they can release dangerous gases to the atmosphere while burying plastics in soil cannot destroy plastics because they are not biodegradable. Degradation at high temperature, such as in pyrolysis (burning) tends to cause emission of toxic fumes. Plastic accumulation in the environment thus creates tremendous problems for the world, presently and in the future. Environmental problems caused by plastics include changes to the carbon dioxide cycle, problems in composting, and increased toxic emissions. Stimulated by environmental concerns, scientists are now concentrating on ways to develop plastics that will be used more efficiently. Two simple strategies are to "recycle" (reuse), or to produce plastics that will degrade when no longer required. Degradable plastics are grouped by the American society for Testing and Materials [1] as:

(a) Photodegradable plastics - a degradable plastic in which the degradation results from the action of natural daylight;

(b) Oxidatively degradable plastics - a degradable plastic in which the degradation results from oxidation;

(c) Hydrolytically degradable plastics - a degradable plastic in which the degradation results from hydrolysis; and

(d) Biodegradable plastics - a degradable plastic in which the degradation results from the action of naturally occurring microorganisms such as bacteria, fungi and algae.

As the plastics defined in categories (a), (b) and (c) require additional inputs, such as light (UV) or oxygen for degradation, the biodegradable plastics (d) offer the only products which are "naturally" degradable. There has been a widespread interest in films made from renewable and natural polymers which can degrade naturally and more rapidly than the petroleum-based plastics. Among all biopolymers, starch is being investigated as a potential material for biodegradable films [2]. Starch consists of two types of polysaccharides, namely amylose and amylopectin. Amylose is a linear molecule with a few branches, whereas amylopectin is a highly branched molecule. Therefore, amylose content contributes to film strength and branched structure of amylopectin generally leads to film with low mechanical properties [3].To increase film flexibility, plasticizers 
are used due to their ability to reduce internal hydrogen bonding between polymer chains while increasing molecular space. The most commonly used plasticizers in starch films are polyols, such as sorbitol and glycerol. The main interest in 'biodegradable' plastics is that they break down into simpler components sooner than traditional plastics[4]. Usually, this means the chemistry of the polymers is such that they degrade into smaller molecules either chemically or by organisms. Biodegradable packaging is packaging that after being used; simply biodegrades harmlessly back into the earth. This helps significantly in reducing the amount of packaging that needs to go to landfill and in addition conserves energy as the biodegrading process does not require external energy. Biodegradable polymers are derived from replenishable agricultural feedstocks, animal sources, marine food processing industry wastes, or microbial sources. In addition to renewable raw ingredients, biodegradable materials break down to produce environmentally friendly products such as carbon dioxide, water, and quality compost [5]. Biodegradable polymers made from cellulose and starches have been in existence for decades, with the 1st exhibition of a cellulose-based polymer (which initiated the plastic industry) occurring in 1862 [6]. Cellophane is the most common cellulose-based biopolymer. Starch-based polymers, which swell and deform when exposed to moisture, include amylose, hydroxylpropylated starch, and dextrin. Other starch-based polymers are polylactide, polyhydroxyalkanoate (PHA), polyhydroxybuterate (PHB), and a copolymer of PHB and valeric acid (PHB/V). Made from lactic acid formed from microbial fermentation of starch derivatives, polylactide does not degrade when exposed to moisture [7]. PHA, PHB, and PHB/V are also formed by bacterial action on starches [8]. In addition, biodegradable films can also be produced from chitosan, which is derived from the chitin of crustacean and insect exoskeletons. Chitin is a biopolymer with a chemical structure similar to cellulose.

Synthetic polymers can also be made partially degradable by blending them with biopolymers, incorporating biodegradable components (such as starches), or adding bioactive compounds. The biocomponents are degraded to break the polymer into smaller components. Bioactive compounds work through various mechanisms. For example, they may be mixed with swelling agents, which expand the molecular structure of the plastic upon exposure to moisture to allow the bioactive compounds to break down the plastic. Starch is an inexpensive and abundant product available in nature. It is totally biodegradable in a wide variety of environments and can be used in the development of totally degradable products for specific market needs. Degradation or incineration of starch products recycles the atmospheric $\mathrm{CO}_{2}$ trapped by starch-producing plants during their growth, thus closing the biological carbon cycle [9]. Cereda et al. [10, 11] showed that the use of cassava starch films was promising, giving a good appearance, without stickiness, exhibiting shininess and transparency. Vicentini et al. [12] developed edible coatings derived from cassava starch to minimize postharvest losses. Cereda et al. [13] characterized coatings of both natural and modified cassava starch using scanning electron microscopy as a method of learning more about their structures when applied to surface of fruits, vegetables and flowers. Andrade et al. [14] developed a new type of composite material, constituted of thermoplastic starch reinforced with chitin. Vicentini et al. [15] also developed edible films based on a mixture of cassava starch and wheat gluten. Rosa et al. [16] reported a methodology for preparing new polymer blends, containing different quantities of starch, with poly (e-caprolactone), poly ( $\square$-hydroxybutyrate) and poly ( $\square-$ hydroxybutyrate-co-b-hydroxyvalerate). Mali et al. [3] developed biodegradable and edible yam starch films. These studies and the references therein report a renewed interest in the research of materials based on starch. The use of cassava would not only create an economic alternative for cassava agriculture but would also lead to a reduction in the impacts caused by the intense use of packaging film derived from oil (polyethylene, polystyrene, etc.). Nigeria being the world largest producer of cassava, production of biodegradable packaging materials is thus, feasible. The objectives of this study were:

1. To produce a biodegradable plastic film from cassava starch;

2. And to determine the biodegradability and tensile strength of the plastic film produced, and compare them with that of polythene and paper.

\subsection{Materials}

\section{MATERIALS AND METHODS}

Materials used for starch production were: cassava tubers obtained from a local market in Nsukka Nigeria, and portable water. Materials used for film production were: cassava starch, polyvinyl alcohol (liquid), talc powder, glycerin, urea and water. The polyvinyl alcohol, talc powder and glycerin were all obtained from No. 8 Limca Road Onitsha, Anambra state, Nigeria. Polyvinyl alcohol (PVA) is a water-soluble polymer made by hydrolysis of a polyvinyl ester (such as polyvinyl acetate). It is used in adhesives, as textile and paper size, and for emulsifying, suspending, and thickening of solutions. Glycerin is a simple polyol compound. It is a colorless, odorless, viscous liquid and has a high boiling point and freezes to form a paste. It is the plasticizer used in the film production. A plasticizer is an additive that softens the material it is added to. Talc or talcum powder is a mineral that is naturally found in nature. It is the lubricant used in this work. It was used for easy 
flow of the mixture in the extruder. Urea was used as crossing link agent, that is, to make the starch and PVA compatible.

Apparatus used for cassava starch production were: knife for manual peeling of cassava tubers, grating machine, sieve, filtering cloth, bowl and oven for the starch drying. And for film preparation, the following apparatus were used: mercury-in-glass thermometer to check the temperature of the starch during melting, infrared moisture meter to determine the moisture content of the starch, electronic balance to weigh the sample materials so as to obtain the desired quantity of materials needed, a container to collect samples to be weighed, a wooden spatula for material mixing, and blown-film extruder for practical production of the biodegradable film. The mechanism of operation consist basically of extruding a tube of molten thermoplastic, and continuously inflating it to several times initial its diameter to form a thin tubular product that can be used directly or slit to form a flat film. The Monsanto tensometer was used to test for the mechanical properties of the film produced. The tensile strength and elasticity of the film were tested and compared with polythene film and paper. The mechanism of operation of this machine consist of attaching the material to be tested in place, then manually applying a force by turning the loading arm of the machine clockwise, which in turn causes the operating screw to move rightward, thus pushing or pulling, depending on the type of test performed. The force is transmitted through a simple lever system to a mercury piston and the reading is indicated through sliding the cursor front or back following the mercury convex head. The movement of the worm gear, which causes deformation of the specimen, is transmitted through a gear train to the recording drum. The rotation of the drum is proportional to the deformation of the test piece. A digital vernier caliper was used to measure the thickness of the materials during testing. Instruments used for testing Total Carbon Concentration (TOC) were $500 \mathrm{ml}$ flask, weighing balance, $50 \mathrm{ml}$ burette, and bulb pipette. A pair of scissors was used to cut the specimen to the desired size.

\subsection{Methodology}

\subsubsection{Cassava Starch Preparation}

Manual peeling and washing of the cassava tubers with portable water was done, followed by mechanical grating of the tubers. The grated cassava was mixed with water ( 3 times the volume of the grated cassava). The mixture was sieved and filtered using a coarse sieve and filter cloth respectively. Thereafter, the filtrate was allowed to settle for six hours. The resulting starch was mixed with water again and allowed to settle for twelve hours. This is called starch washing. At the twelfth hour, it was decanted. The starch (wet) was dewatered manually and then oven-dried in the Food and Bioprocessing laboratory of Agricultural and Bioresources Engineering Department, University of Nigeria, Nsukka.. It was dried at a temperature of $105^{\circ} \mathrm{C}$ for 4 hours. This was to make sure the starch was in its barest minimum moisture content.

\subsubsection{Film Preparation}

The cassava starch was first tested for moisture content using infra-red moisture meter and it was found to contain $12 \%$ moisture. This was done in order to ensure that the starch contains not more than $13 \%$ moisture. A mixture of $1 \mathrm{~kg}$ powdered cassava starch, $2 \mathrm{~kg}$ polyvinyl alcohol liquid, $100 \mathrm{~g}$ talc powder, and $100 \mathrm{~g}$ urea was prepared. The resulting mixture was added to $400 \mathrm{ml}$ of glycerin. The whole mixture was stirred to yield a semi dry powder. Thereafter, the mixture was then extruded with a Blown film extruder to produce a biodegradable film, which can either be used directly or modified/processed further for use. The production was carried out at Mac Terry Film production Factory Onitsha, Ezi Zik Awada, Anambra state, Nigeria. The film was produced under the following conditions: Zone 1 temperature of $190^{\circ} \mathrm{C}$, Zone 2 Temperature of $220^{\circ} \mathrm{C}$, Melt Temperature of $200^{\circ} \mathrm{C}$, Film die diameter of $300 \mu \mathrm{m}$, and Extruder speed of 60rpm.

\subsubsection{Test for Validity of the Biodegradable Film}

Two tests were performed for the product validity. These include: test for tensile strength, and test for biodegradability. In conducting the tests, comparison of the biodegradable film was made with two other materials, namely paper and polythene films.

(i) Test for Tensile Strength: The test was carried out at the Strength of Material Section, Civil Engineering Laboratory, University of Nigeria, Nsukka. A Hounsfield (Monsanto) tensometer was used to test for the tensile strength of the biodegradable film. Two other specimens (polythene and paper) were tested, and their strength compared with that of the biodegradable film. The three specimens were cut into the same specific sizes of $100 \mathrm{~mm}$ length and $19 \mathrm{~mm}$ breadth.

(ii) Test for Biodegradability: The test was carried out using the Total Organic Carbon Test procedure at Hezekiah Consulting Laboratory opposite Bishop Shanahan Hospital Nsukka, Enugu state, Nigeria. The three samples tested were cut into tiny pieces, and $0.02 \mathrm{~g}$ weight each was used to perform the tests. Each sample was identified with a letter of the alphabet. Thus, biodegradable film, polythene and paper were tagged A, B, C respectively. The samples were each put in a $500 \mathrm{ml}$ conical flask. A fourth conical flask with no sample was also tagged, D (Blank). The forth conical flask was used in order to make sure that what was being looked for 
was there in the samples. $10 \mathrm{ml}$ of 1 normal potassium dichromate $\left(\mathrm{K}_{2} \mathrm{Cr}_{2} \mathrm{O}_{7}\right)$ was pipetted and added to each of the samples including the blank and swirled. After, $20 \mathrm{ml}$ of sulphuric acid was added also to each and allowed to cool for about 30 minutes. Then $200 \mathrm{ml}$ of distilled water was equally added to each (sample and blank). $1 \mathrm{~g}$ of sodium fluoride (NaF) was added to each sample and the blank and allowed to cool for about 15minutes. Thereafter, $1 \%$ of Diphenylamine indicator was added which turned the samples black. Titration of both the samples and the blank was done using 1 Normal ferrous sulphate solution. Titration of each was stopped when its colour changed from black to green and then the values of the titre were recorded.

\section{RESULTS, ANALYSES AND DISCUSSIONS}

\subsection{Results of Tensile Strength Test}

The tensile strength of the film produced was tested and compared with two other packaging materials; polythene and paper. The individual specimens were cut into $100 \mathrm{~mm}$ length and $19 \mathrm{~mm}$ breadth each and their thickness were also measured. The values of the thickness are given below: Biodegradable film $(0.02 \mathrm{~mm})$, Polythene $(0.015 \mathrm{~mm})$, Paper $(0.02 \mathrm{~mm})$.

Table 1: Tensile strength test result for the biodegradable film

\begin{tabular}{|l|l|l|l|}
\hline FORCE, F $(\mathrm{N})$ & $\begin{array}{l}\text { EXTENSION,EXT } \\
(\mathrm{mm})\end{array}$ & $\begin{array}{l}\text { STRESS, } \delta=\mathrm{F} / \mathrm{A} \\
\left(\mathrm{N} / \mathrm{mm}^{2}\right)\end{array}$ & STRAIN, $\varepsilon=$ EXT/L \\
\hline 0.00 & 0.00 & 0.00 & 0.00 \\
\hline 6.30 & 0.25 & 16.58 & $7.50 \mathrm{exp}-3$ \\
\hline 7.88 & 2.13 & 20.74 & $2.13 \mathrm{exp}-2$ \\
\hline 9.45 & 5.00 & 24.87 & $5.00 \mathrm{exp}-2$ \\
\hline 9.45 & 8.25 & 24.87 & $8.25 \mathrm{exp}-2$ \\
\hline 9.45 & 11.75 & 24.87 & $1.17 \mathrm{exp}-1$ \\
\hline 9.45 & 16.50 & 24.87 & $1.65 \mathrm{exp}-1$ \\
\hline 9.45 & 22.50 & 24.87 & $2.25 \mathrm{exp}-1$ \\
\hline
\end{tabular}

Table 2: Tensile strength test result for polythene

\begin{tabular}{|l|l|l|l|}
\hline FORCE, F (N) & $\begin{array}{l}\text { EXTENSION, EXT } \\
(\mathrm{mm})\end{array}$ & $\begin{array}{l}\text { STRESS, } \delta=\text { F/A STRAIN, } \varepsilon=\text { EXT/L } \\
\left(\mathrm{N} / \mathrm{mm}^{2}\right)\end{array}$ & S \\
\hline 0.00 & 0.00 & 0.00 & 0.00 \\
\hline 1.58 & 0.78 & 5.45 & $7.50 \mathrm{exp}-3$ \\
\hline 3.15 & 2.75 & 10.86 & $2.80 \mathrm{exp}-2$ \\
\hline 3.15 & 6.25 & 10.86 & $6.30 \mathrm{exp}-2$ \\
\hline 3.15 & 8.00 & 10.86 & $8.00 \mathrm{exp}-2$ \\
\hline 3.15 & 10.75 & 10.86 & $1.08 \mathrm{exp}-1$ \\
\hline 3.15 & 16.50 & 10.86 & $1.65 \mathrm{exp}-1$ \\
\hline 3.15 & 20.50 & 10.86 & $2.05 \mathrm{exp}-1$ \\
\hline
\end{tabular}

Table 3: Tensile strength test result for paper

\begin{tabular}{|l|l|l|l|}
\hline FORCE, F $(\mathrm{N})$ & $\begin{array}{l}\text { EXTENSION, EXT, } \\
(\mathrm{mm})\end{array}$ & $\begin{array}{l}\text { STRESS, } \delta=\text { F/N } \\
\left(\mathrm{N} / \mathrm{mm}^{2}\right)\end{array}$ & STRAIN, $\varepsilon=\mathrm{EXT} / \mathrm{L}$ \\
\hline 0.00 & 0.00 & 0.00 & 0.00 \\
\hline 3.15 & 1.00 & 8.29 & $1.00 \mathrm{exp}-2$ \\
\hline 3.15 & 2.00 & 8.29 & $2.00 \mathrm{exp}-2$ \\
\hline 3.15 & 2.88 & 8.29 & $2.88 \mathrm{exp}-2$ \\
\hline
\end{tabular}

Tables 1, 2 and 3 show the results of the tensile strength tests performed on the biodegradable film, polythene, and paper respectively, displaying the forces applied and their extensions with their corresponding stress and strain calculated. The calculations were gotten by interpreting the graph used in running the test. Lesser number of values was obtained for paper material because it failed before completing a cycle while that of the biodegradable film and polythene had higher numbers because they were able to stand the force applied and therefore did not fail before completing a cycle. Calculating the tensile strength of each material:

Tensile strength of $\mathrm{A}=9.45 /(19 \times 0.02)=24.87 \mathrm{~N} / \mathrm{mm}^{2}$

Tensile strength of $\mathrm{B}=3.15 /(19 \times 0.015)=10.86 \mathrm{~N} / \mathrm{mm}^{2}$

Tensile strength of $\mathrm{C}=3.15 /(19 \times 0.02)=8.29 \mathrm{~N} / \mathrm{mm}^{2}$

From the results, it can be observed that specimen ' $A$ ' which is the biodegradable film has the highest tensile strength and this could be as a result of the glycerol used in the film production which was added to 
improve its mechanical strength. The strength is much higher than that of polythene. The paper (specimen C) has the least tensile strength, therefore it failed at a very short period of time when load was applied. Figs. 1, 2 and 3 show the stress-strain curve of the biodegradable film, polythene and the paper respectively. The stressstrain curve is a graphical representation of the relationship between stress, derived from measuring the load applied on the sample, and strain, derived from measuring the deformation of the sample, i.e. elongation. The slope of the elastic (linear) portion of the curve is a property used to characterize materials and is known as the Young's modulus. It can be seen also from the graphs plotted that the biodegradable film produced showed a higher mechanical strength than that of the polythene and hence can substitute it (that is; the conventional plastics used for packaging).

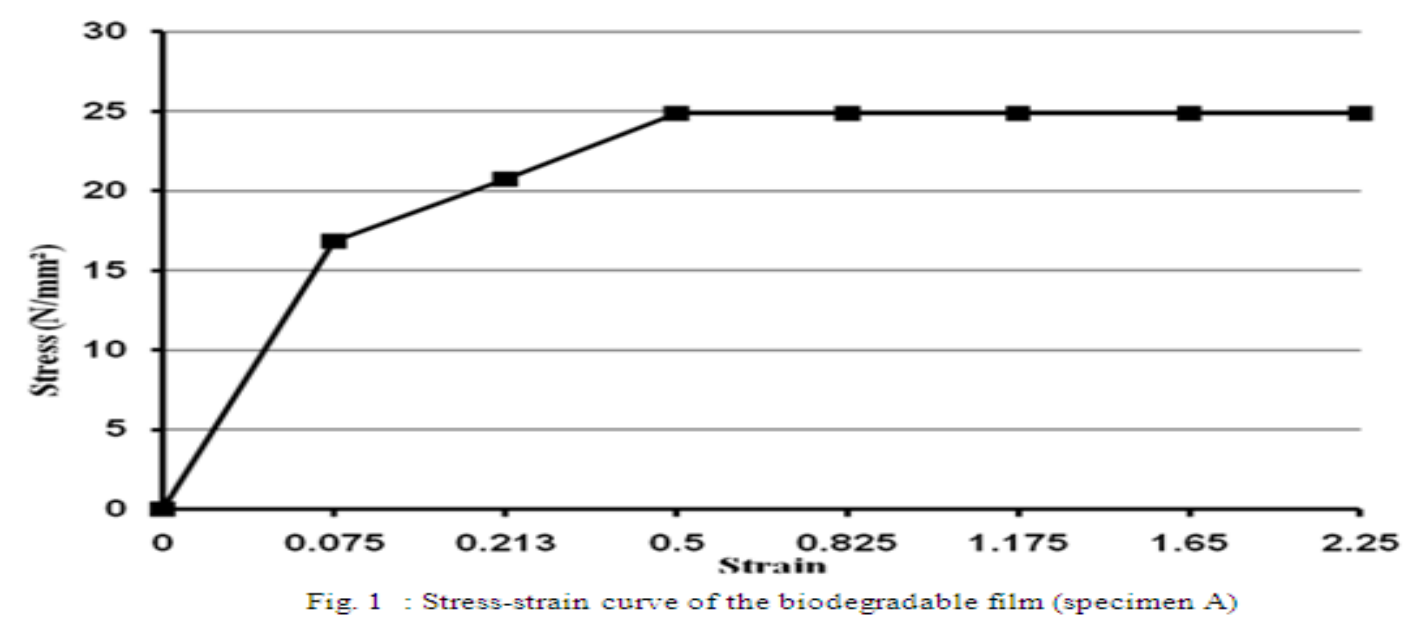

\subsection{Results of Biodegradability Test}

Table 4: Biodegradable test results of the materials

\begin{tabular}{|l|l|l|l|}
\hline SAMPLE & INITIAL VALUE, $(\mathrm{I})$ & FINAL VALUE, $(\mathrm{F})$ & TITRE VALUE $(\mathrm{F}-\mathrm{I})$ \\
\hline $\mathrm{A}$ & 4.30 & 13.90 & 9.60 \\
\hline $\mathrm{B}$ & 13.90 & 24.40 & 10.50 \\
\hline $\mathrm{C}$ & 24.40 & 32.70 & 8.30 \\
\hline $\mathrm{D}$ (Blank) & 3.50 & 14.30 & 10.80 \\
\hline
\end{tabular}

From Table 4, it is observed that the titre value of the blank is higher than others. This indicates that samples A, $\mathrm{B}, \mathrm{C}$ contain the organic matter which is being looked for.

The $\%$ carbon content of the material is given by equation (1):

$\%$ carbon $=$ Titre difference $\times 0.003 \times 1.33 \times 100 / \mathrm{wt}, \mathrm{wt}=0.02 \mathrm{~g}$

Where:

- $\quad$ Titre difference $=$ Blank titre value - titre value of each of the material

- $\quad 0.003$ equals 1 normal $\mathrm{K}_{2} \mathrm{Cr}_{2} \mathrm{O}_{7}=3 \mathrm{mg}$ carbon

- $\quad 1.33$ equals correction factor

- $\quad \mathrm{wt}=$ weight of sample $=0.02 \mathrm{~g}$ each

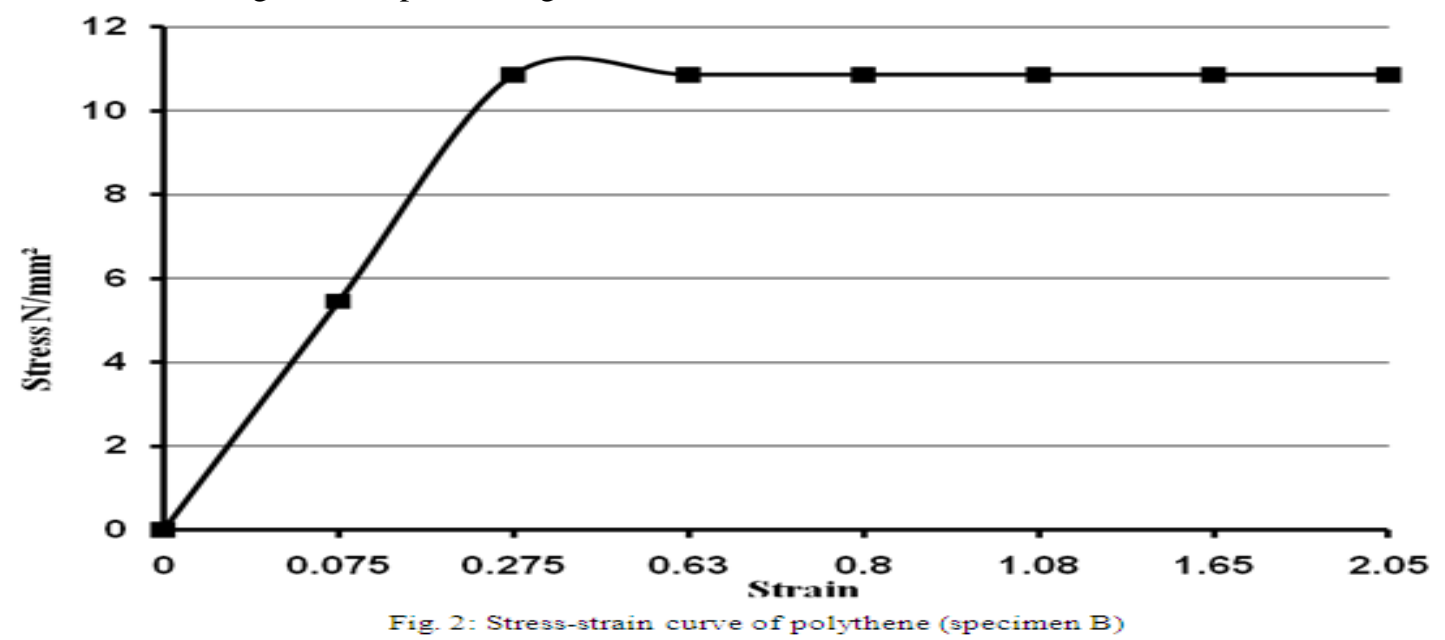




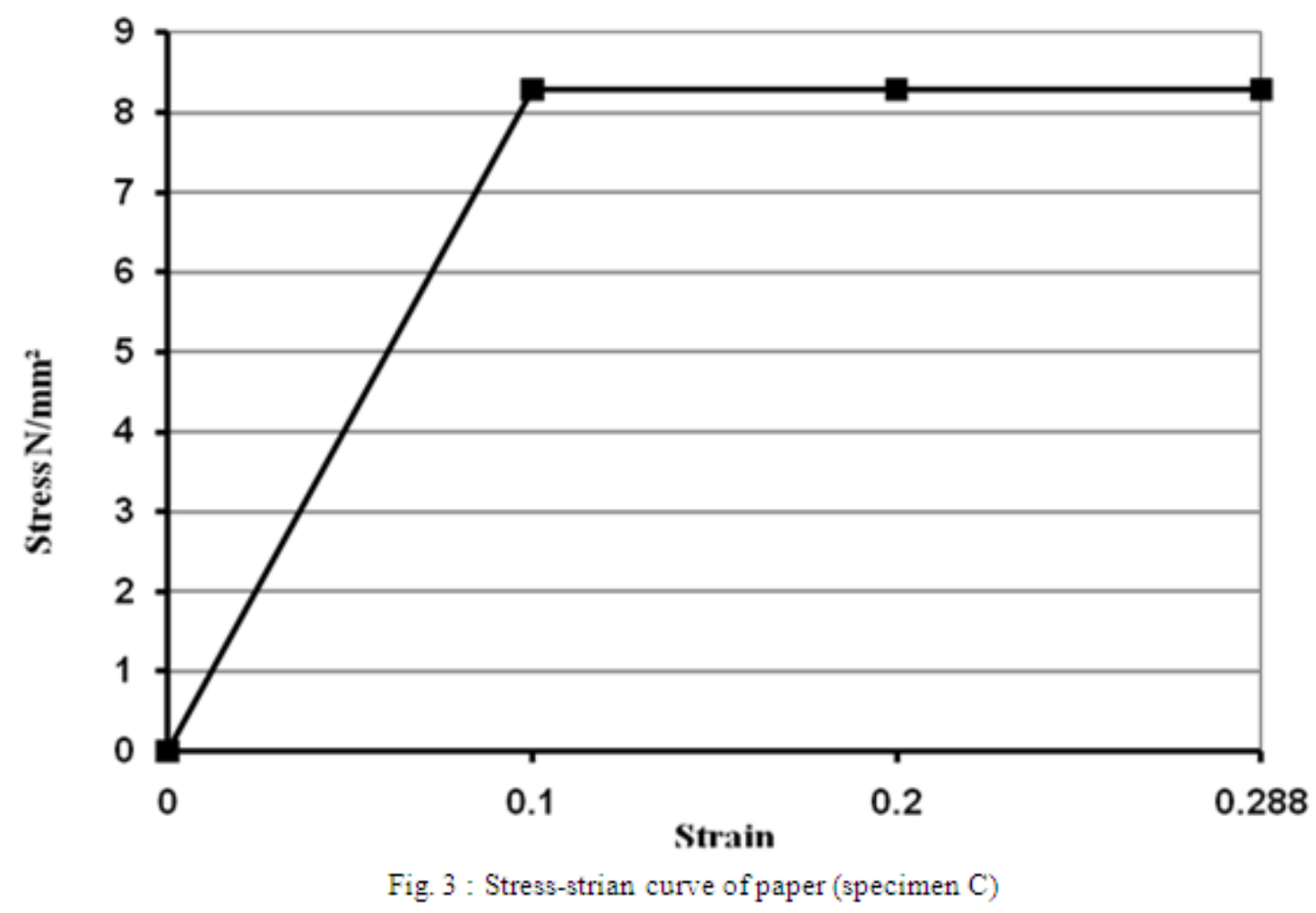

That is, titre values are 1.2 for A (i.e.10.80 - 9.60), 0.3 for B (i.e.10.80 - 10.50), and 2.5 for C (i.e. 10.80 $8.30)$. The percent organic matter is given by equation (2):

$\%$ organic matter $=\%$ carbon $\times 1.724$

Where 1.724 is from the relationship; $100 \mathrm{~g}$ of carbon $=58 \mathrm{~g}$ of organic matter.

For A, \%carbon $=1.2 \times 19.95=23.94 \%$; and $\%$ organic matter $=23.94 \times 1.724=41.27 \%$

For B, \%carbon $=0.3 \times 19.95=5.99 \%$; and $\%$ organic matter $=5.99 \times 1.724=10.33 \%$

For $\mathrm{C}, \%$ carbon $=2.5 \times 19.95=49.88 \%$; and $\%$ organic matter $=49.88 \times 1.724=85.99 \%$.

From the results of the calculations above, it can be seen that, specimen $\mathrm{C}$, paper contains more organic matter than the other two specimen, hence it can biodegrade more quickly. Specimen A (biodegradable film) contains more organic matter than specimen B (polythene) and this could be as a result of the starch content.

\subsection{Conclusions}

\section{CONCLUSIONS AND RECOMMENDATIONS}

Without question, the challenges surrounding plastics waste treatment are multifaceted and complex and, as numerous studies have indicated, are further being compounded as time progresses. It will be up to future generations of society to produce the necessary resources to address this growing environmental concern with viable, long-term solutions. Truly innovative global research and development has resulted in today's emerging field of bioplastics. By combining the disciplines of Engineering, Agriculture, Food packaging, and Chemistry, new biodegradable packaging solutions from renewable plant resources will help to address this environmental concern of rampant worldwide growth in plastic wastes.

(1) It is important to recognize that although past and recent efforts have thus far yielded significant strides in the field of bioplastics, continued research in this field is clearly needed if economically-viable development and sustainable production processes are to be widely implemented throughout the world.

(2) As with any emerging technology, continued innovation and global support is essential in order for bioplastics to fully demonstrate its socioeconomic benefits and further challenge the status quo of traditional petroleum-based plastics.

(3) The use of biodegradable plastics is however, a sure solution to the problems of plastic waste accumulation as it is economically viable and not harmful to our environment as the waste can readily decompose in the soil and the decomposed waste can be used as manure for growing crops, starchy crops inclusive which are raw materials for bioplastic production.

(4) The future of biodegradable plastics shows great potential. How widespread biodegradable plastics will be used all depends on how strongly society embraces and believes in environmental preservation. Many countries 
around the world have already begun to integrate these materials into their markets. There are certainly abundant amount of materials and resources to create and fund more uses for biodegradable plastics. The increasing interest will allow the technology needed to produce biodegradable plastics become more affordable and the falling production costs will eventually lead to an increase in production.

(5) The present research has demonstrated that biodegradable plastic packaging films can be produced from cassava starch, and it could serve as a good substitute for the conventional plastic packaging films.

\subsection{Recommendations:}

Even though a biodegradable plastic packaging film was produced in this work, a better result would have been obtained if the necessary techniques and equipment needed were available. The polymer, PVA used is not commonly found and if found it is costly. Polylactic acid possesses several desirable properties such as biodegradability, biocompatibility, compostability, and low toxicity to humans than other suitable polymers. It was not used because the techniques used in producing it were not available locally. It is therefore recommended that there is a dire need to design and produce all the required equipment needed for production of Polylactic acid and also to design Blown film extruders which are used to produce the final product since the existing ones were designed for foreign conventional plastic raw materials.

Finally, more research should be continued in this field, especially in developing countries so that we can have cleaner nations by reducing the conventional plastic waste in the environment.

\section{REFERENCES}

[1] ASTM Standards, Vol. 08.01. (1998). D883-96: Standard Terminology Relating To Plastics. New York, NY.

[2] L Averous,L. Moro, P. Dole, and C. Fringant, Properties of thermoplastic blends: Starchpolycaprolactone. Polymer, 41, 2000, 4157-4167.DOI: 10.1016/S0032-3861(99)00636-9

[3] S Mali, M.V.E. Grossmann, M.A. Garcia, M.N. Martino,and N.E. Zaritzky, Microstrucural characterization of yam starch films. Carbohydrate Polymers, 50, 2002, 379-386.

[4] C. Bastioli, Handbook of biodegradable polymers(Toronto-Scarborough,Ontario,Canada: ChemTec Publishing, 2005).

[5] R.N. Tharanathan, Biodegradable films and composite coatings: Past, present, andfuture. Trends in Food Science and Technolog, 14, 2003, 71-78.

[6] D.C. Miles and J.H. Briston, Polymer technology(NewYork: Chemical Publishing Co. Inc., 1965).

[7] R Auras, B. Harte, S. Selke, An overview of polyactides as packaging materials. Macromol Biosci 4(9), 2004,835-64.

[8] J.M. Krochta, C. DeMulder-Johnston, Edible and biodegradable polymer films: challenges and opportunities [IFT scientific status summary]. Food Tech 51(2), 1997, 61-74.

[9] C Bastioli,Properties and applications of Mater-Bi starch based materials, Polymer Degradation and Stability, 59, 1998, 263-272.

[10] M.P. Cereda, A.C. Bertolini, and R.M. Evangelista, Uso do amido em substituição às ceras na elaboração de filmes na conservação pós-colheita de frutas e hortaliças: estabelecimento de curvas de secagem. In: 7. Congresso Brasileiro de Mandioca. (Anais... (Recife, 1992) 107.

[11] M.P. Cereda, A.C. Bertolini, A.P. Silva, M.A. Oliveira, and R.M. Evangelista, Películas de almidón para la preservación de frutas. In: Congresso Polimeros Biodegradables:Avances y Perspectivas(Anais... Buenos Aire, 1995) 42.

[12] N.M. Vicentini, M.P. Cereda,andF.L.A. Câmara, Revestimentos de fécula de mandioca, perda de massa e alteração da cor de frutos de pimentão. Scientia Agrícola, 56 (3),1999, 13-716.

[13] M.P. Cereda, C.M. Henrique, M.A. Oliveira, M.V. Ferraz, and N.V. Vicentini, Characterization of edible films of cassava starch by electron microscopy. Brazilian Journal of Food Technology, 3,2000, 91-95.

[14] C.T. Andrade, R.C.R Souza, L.C. Barbosa, and K.M.P. Silva, (2000), Use of chitin as reinforcing material in biodegradable thermoplastic starch. In: Natural Polymers and Composites(São Paulo: Embrapa Instrumentação Agropecuária, 2000).

[15] N.M. Vicentini, P.J.A. Sobral, andM.P. Cereda, (2001): Desenvolvimento de filmes comestíveis a base de misturas de fécula de mandioca e glúten de trigo. In: 4. Simpósio Latino Americano de Ciência de Alimentos. (Resumos... Campinas: FEA/UNICAMP, 2001) 183 - 183.

[16] D.V. Rosa, B.L.M. Franco, and M.R. Calil, Biodegradabilidade e propriedades mecânicas de novas misturas poliméricas: polímeros. Ciência e Tecnologia, 11(2), 2001, 82-88. 